\title{
Clinical and Biological Heterogeneity in Children with Moderate Asthma
}

\author{
Stefania La Grutta, Rosalia Gagliardo, Franco Mirabella, Giovanni Battista Pajno, Giovanni Bonsignore, \\ Jean Bousquet, Vincenzo Bellia, and Antonio Maurizio Vignola
}

Istituto di Medicina Generale e Pneumologia, Università di Palermo; Istituto di Fisiopatologia Respiratoria, CNR; Allergy Unit, Children Hospital, ARNAS, Palermo; Istituto di Clinica Pediatrica, Università di Messina, Italy; Institut National de la Santé et de la Recherche Médicale U-454, Montpellier, France

\begin{abstract}
To evaluate the relationship between inflammatory markers and severity of asthma in children, the amount of interleukin-8 (IL-8) and granulocyte/macrophage colony-stimulating factor (GM-CSF) released by peripheral blood mononuclear cells, exhaled nitric oxide (FE NO) levels, p65 nuclear factor-кB subunit, and phosphorylated $\mathrm{lkB} \alpha$ expression by peripheral blood mononuclear cells were assessed in six control subjects, 12 steroid-naives subjects with intermittent asthma, and 17 children with moderate asthma. To investigate their predictive value, biomarker levels were correlated with the number of exacerbations during a 18-month follow-up period. We found that GM-CSF release was higher in moderate and intermittent asthmatics than in control subjects, whereas IL-8 release was higher in moderate than in intermittent asthmatics and control subjects. FE NO levels were similar among study groups. In moderate asthmatics, IL-8, GM-CSF, and FE NO significantly correlated with the exacerbation numbers. Moreover, p65 and phosphorylated IkB $\alpha$ levels were greater in moderate than in intermittent asthmatics and control subjects. According to GM-CSF, IL-8, and FE NO levels, two distinct subgroups of moderate asthmatics (low and high producers) were identified. High producers experienced more exacerbations than low producers. This study shows ongoing inflammation associated with biological and clinical heterogeneity in moderate asthmatics despite regular treatment and proposes that large prospective studies confirm the importance of biomarkers to assess inflammation and asthma control in children with asthma.
\end{abstract}

Keywords: asthma; inflammatory markers; fluticasone propionate

The identification of biomarkers measured using non- or minimally invasive methods represents an important goal in the management of childhood asthma for several reasons. First, inflammatory and structural changes of the airways occur very early in asthma; second, the long-term management of childhood asthma is still debated (1-3); third the risk/benefit ratio of a prolonged treatment with high steroid doses can be problematic (4-6); fourth, clinical subpopulations exist in children with severe asthma (7). The persistence of airway inflammation in asthma is likely to be due to the sustained transcription and production of inflammatory mediators. Among transcription factors, nuclear factor- $\kappa \mathrm{B}(\mathrm{NF}-\kappa \mathrm{B})$ plays an important role in airway inflammation (8-10) and activates the transcription of several genes. NF-кB activation is inhibited by endogenous cytoplasmic inhibitors, known as IkBs. The most characterized NF- $\mathrm{KB}$ inhibitor is $\mathrm{IkB} \alpha$, which binds avidly to the p65 (RelA) subunit of $N F-\kappa B$, precluding its nuclear translocation and transcriptional activity. The dissociation of $\mathrm{IkB} \alpha$ from $\mathrm{NF}-\kappa \mathrm{B}$

(Received in original form June 12, 2002; accepted in final form January 28, 2003) Correspondence and requests for reprints should be addressed to A. Maurizio Vignola, M.D., Ph.D., Istituto di Medicina Generale e Pneumologia, Università di Palermo, Via Trabucco 180, 90146 Palermo, Italy. E-mail: vignola.am@iol.it

Am I Respir Crit Care Med Vol 167. pp 1490-1495, 2003

Originally Published in Press as DOI: 10.1164/rccm.200206-5490C on February 5, 2003 Internet address: www.atsjournals.org is due to $\mathrm{IkB} \alpha$ phosphorylation, polyubiquitinylation, and rapid degradation by proteasome. As a result, NF- $\mathrm{B}$ translocates to the nucleus and activates transcription of target genes, increasing the expression of inflammatory mediators (11). Among them, granulocyte/macrophage colony-stimulating factor (GM-CSF) and interleukin-8 (IL-8) have been shown to play an important role in asthma, and in particular in persistent severe asthma $(12,13)$. Inflammation in the airways can also be reflected by the levels of nitric oxide in exhaled air (FE NO) (14).

Glucocorticosteroids are powerful antiinflammatory drugs, which by interacting with transcription factors such as NF-кB, repress the activation of proinflammatory genes (15). Inhaled corticosteroids represent the best treatment of asthma. However, at recommended doses, although they usually control symptoms and improve lung function, they have an incomplete efficacy on airway inflammation and bronchial hyperresponsiveness (16). To evaluate the relationship between minimally invasive markers of airway inflammation with asthma severity in children, we undertook a pilot study in which the release of IL-8 and GM-CSF by peripheral blood mononuclear cells (PBMC), as well as the levels of FE NO, were assessed at study entry in children with intermittent and moderate asthma who were clinically well controlled and receiving high doses of inhaled corticosteroids and long-acting $\beta 2$ agonists. We then examined whether the in vitro production of IL-8 and GMCSF by these cells was sensitive to pyrrolidinedithiocarbamate, an inhibitor of NF- $\mathrm{B}$ activation (17). Finally, to better characterize the activation of NF- $\mathrm{KB}$ pathway, we analyzed the expression of $\mathrm{p} 65 \mathrm{NF}-\kappa \mathrm{B}$ subunit and of the phosphorylated form of $\mathrm{IkB} \alpha(\mathrm{p}-\mathrm{IkB} \alpha)$ in PBMC of the study groups. Finally, the biological parameters examined were correlated with the number of exacerbations occurring during a follow-up period of 18 months.

\section{METHODS}

\section{Subjects}

Twenty-nine asthmatics $(6-14$ years, mean \pm SD: $9.6 \pm 2.3)$ were recruited from an outpatient clinic. The diagnosis of asthma and the assessment of its severity were done at study entry according to Global Initiative for Asthma 1995 (18). Twelve children had intermittent asthma, treated with short-acting $\beta 2$ agonists on demand during the last 6 months preceding the study; 17 children had moderate persistent asthma, treated with fluticasone propionate $250 \mathrm{mg}$ (inhaler device Diskus [GlaxoSmithKline, London, UK]) plus salmeterol $50 \mu \mathrm{g}$ twice daily for at least 6 months before their inclusion in the study. The control group consisted of six healthy children (7-11 years, mean \pm SD: $9.5 \pm 1.3$ ). The study was approved by our local ethics committee, and written consent was obtained from parents.

\section{Clinical Assessment of the Patients}

Pulmonary function tests were performed as recommended by American Thoracic Society (19). The results are given in percentage of predicted value (20). Atopic status was assessed by skin prick tests (21) 
and specific IgE to aeroallergens commonly present in the Palermo area. The compliance to the therapy was assessed by checking the inhalation technique at every visit. We also measured in the three study groups basal plasma cortisol concentration at 8:00 A.M. $(22,23)$ by electrochemiluminescence (24), at study entry and at the end of the followup period. Results were expressed in nanomolar concentrations, and adherence was considered satisfactory if cortisol was less than $100 \mathrm{nM}$.

\section{Production of Cytokines by PBMC}

PBMC isolated by Ficoll-Hypaque gradient centrifugation were cultivated as described previously (13) in the absence or presence of pyrrolidinedithiocarbamic acid. All supernatants were stored at $-80^{\circ} \mathrm{C}$, and cytokines

A

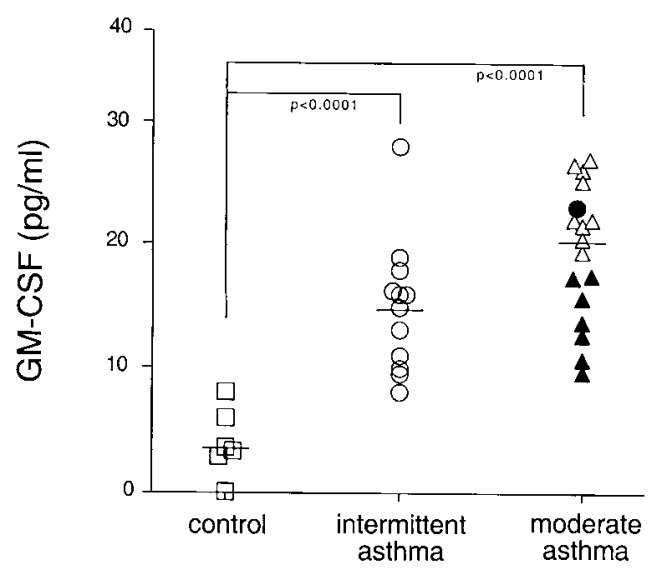

B

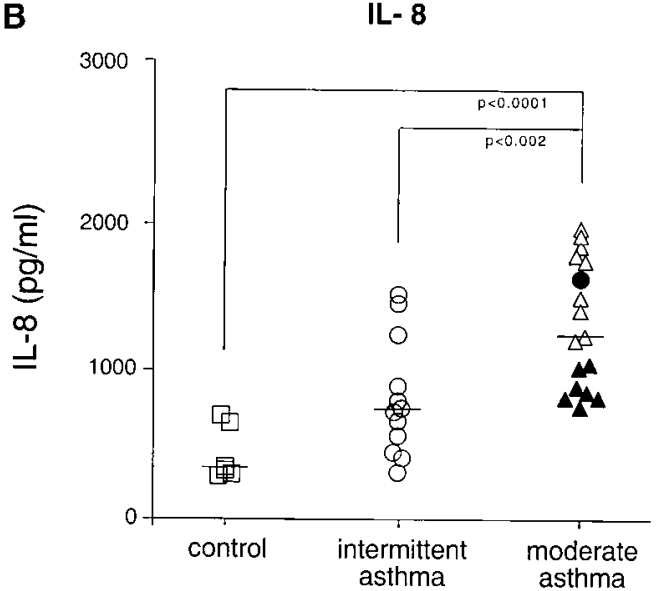

C

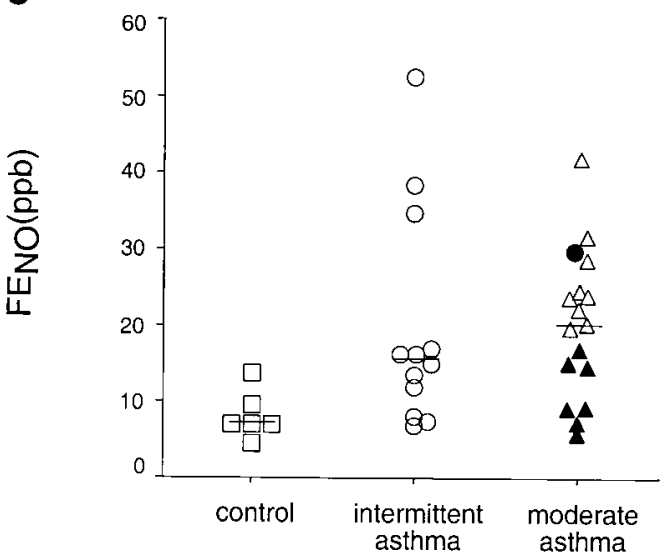

were quantified by enzyme-linked immunosorbent assay (R\&D Systems, Oxon, UK) after the end of the study.

\section{Nitric Oxide Measurement}

FE NO was determined by chemiluminescence (Sievers Instruments Inc, Boulder, CO, USA) and measured in triplicate after fast inhalation maneuvers to total lung capacity, at a constant expiratory flow of $100 \mathrm{ml} /$ seconds against an expiratory resistance of $20 \mathrm{~cm}$ water (25).

\section{Western Blotting}

Western blot analyses were performed as described previously (13).

\section{Study Design}

This was a study in which several biomarkers (IL-8 and GM-CSF released by PBMC, p65 and p-IkB $\alpha$ protein level in PBMC, and FE NO) were measured in 29 children with asthma at study entry; these markers were then correlated with asthma control assessed longitudinally by the number of exacerbations during a follow-up period of 18 months. After a month of run-in period, during which $\mathrm{FEV}_{1}$ before and after bronchodilatation (400 $\mu \mathrm{g}$ of salbutamol) was assessed, patients attended the out-patient clinic (visit 1) and underwent clinical assessment (pre- and postbronchodilator $\mathrm{FEV}_{1}$ ) at 3, 6, 12, and 18 months by the same physician (S.L.G.), who was unaware of the results on biomarker measurements. During the follow-up period, mild and severe exacerbations were defined, according to the Formoterol and Corticosteroids Establishing Therapy study (26). At the beginning of the study, the parents were instructed to refer to our center if any exacerbation occurred. Severe exacerbations were treated with a short course of oral steroids $(1 \mathrm{mg} / \mathrm{kg}$ of prednisolone for 5 days).

\section{Statistical Analysis}

Nonparametric tests were used.

\section{RESULTS}

\section{Patient Characteristics}

All asthmatic children were monosensitized to house dust mites (Table 1). Evidence of satisfactory adherence to therapy was obtained in all but one patient, who was excluded from the followup analysis.

\section{GM-CSF and IL-8 Production}

GM-CSF production by PBMC was similar in children with moderate and intermittent asthma and significantly higher than in children in the control group $(\mathrm{p}<0.001)$ (Figure 1A). IL-8 release by $\mathrm{PBMC}$ was higher in childen with moderate asthma than in children with intermittent asthma and children in the control group ( $\mathrm{p}<0.002$ and $\mathrm{p}<0.0001$, respectively) (Figure 1B).
Figure 1. Release of granulocyte/macrophage colony-stimulating factor (GM-CSF) and interleukin-8 (IL-8) by peripheral blood mononuclear cells (PBMC) and levels of exhaled nitric oxide (FE NO). Assessment of the concentrations of IL-8 $(A)$ and GM-CSF $(B)$ released by PBMC and of levels of FE NO $(C)$ in eight normal children, 12 children with intermittent asthma, and 17 children with moderate asthma. Individual data are shown. Horizontal lines represent the median. Within the moderate asthmatic group, two distinct subgroups of children were observed according to the levels of GM-CSF and IL-8: one (low producers) characterised by a low release of both mediators by PBMC (IL8 < 1,100 ng/ml; GM-CSF < $19 \mathrm{pg} / \mathrm{ml}$ ); another subgroup (high producers) characterised by a high release of both mediators (IL8 $>1,100 \mathrm{ng} / \mathrm{ml}$; GMCSF $>19 \mathrm{pg} / \mathrm{ml}$ ). In the figure, closed triangles show low producers moderate persistent asthmatics whereas open triangles show high producers moderate persistent asthmatics. Closed circles: child with noncompliant moderate persistent asthma. Statistical analysis and $p$ values were assessed without including the noncompliant subject. 
TABLE 1. DEMOGRAPHIC CHARACTERISTICS OF SUBJECTS

\begin{tabular}{|c|c|c|c|c|c|c|}
\hline & \multirow[b]{2}{*}{ Controls } & \multirow{2}{*}{$\begin{array}{l}\text { Intermittent } \\
\text { Asthma }\end{array}$} & \multirow{2}{*}{$\begin{array}{l}\text { Moderate } \\
\text { Asthma }\end{array}$} & \multicolumn{3}{|c|}{$\mathrm{p}$ Value } \\
\hline & & & & $\mathrm{C} / \mathrm{IA}$ & $\mathrm{C} / \mathrm{MA}$ & $\mathrm{IA} / \mathrm{MA}$ \\
\hline Number & 6 & 12 & 17 & & & \\
\hline Sex, M/F & $4 / 2$ & $12 / 5$ & $8 / 4$ & & & \\
\hline Age & $10(9-10)$ & $9(8-10)$ & $9(8-13)$ & NS & NS & NS \\
\hline Total IgE (KU) & $20(15-20)$ & $490(335-450)$ & $500(407-600)$ & $p<0.02$ & $\mathrm{p}<0.001$ & NS \\
\hline $\mathrm{FEV}_{1}(\%)$ & $100(100-102)$ & $98(93-105)$ & $96(89-114)$ & NS & NS & NS \\
\hline Asthma duration, yr & NA & $2(1-4)$ & $4(2-6)$ & & & NS \\
\hline Exacerbations* & 0 & $1(1-2)$ & $2(1.75-3.25)$ & & & NS \\
\hline Cortisol $(\mathrm{nM})^{\dagger}$ & $346(215-458)$ & $194(170-225)$ & $66(58-95)$ & $p<0.001$ & $\mathrm{p}<0.0001$ & $p<0.004$ \\
\hline Cortisol $(n M)^{\ddagger}$ & $342(215-447)$ & $195(170-225)$ & $69(56-95)$ & $\mathrm{p}<0.02$ & $p<0.0001$ & $p<0.004$ \\
\hline
\end{tabular}

Results are expressed as median and (25-75 percentiles).

* Number of exacerbations over the 18 months of the study.

† Cortisol levels at study entry.

‡ Cortisol levels at the end of the follow-up period (18 months).

\section{FE NO Measurements}

The levels of FE NO were nonsignificantly increased in both children with intermittent and moderate asthma in comparison with control subjects (Table 1 and Figure 1).

\section{Biological and Clinical Heterogeneity in Children with Moderate Asthma}

Two distinct subgroups of children with moderate asthma were observed: low producers, characterized by low mediator release (IL-8 $<1,100$ pg/ml; GM-CSF $<19$ pg/ml) (Figures 1A and 1B) and low FE NO levels ( $<20 \mathrm{ppb}$ ) (Figure 1C), and high producers, characterized by a high mediator release and high FE NO levels (IL-8 > 1,100 pg/ml; GM-CSF > 19 pg/ml; FE NO > 20 ppb) (Figures 1A-1C). Pyrrolidinedithiocarbamate treatment inhibited IL-8 release by $52 \%$ for high producers and $32 \%$ for low producers, and GM-CSF release by $40 \%$ for high producers and $24 \%$ for low producers $(\mathrm{p}<0.001$ ) (Figure 2). In high producers (but not in low producers) postbronchodilator $\mathrm{FEV}_{1}$ significantly diminished by the end of the study $(p<0.005)$ (Figure 3 ).

\section{Protein Levels of NF-кB p65 Subunit and p-IkB $\alpha$ Protein}

The relative amount of $\mathrm{p} 65$ and $\mathrm{p}-\mathrm{IkB} \alpha$ protein was higher in children with moderate asthma than in children with intermittent
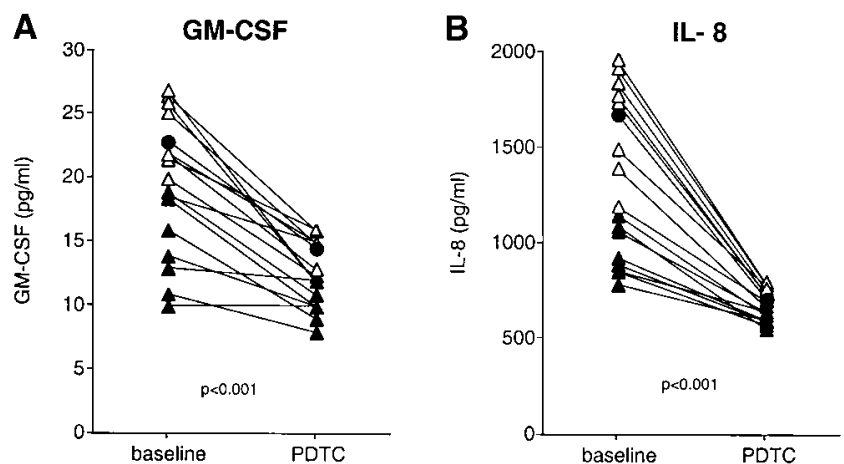

Figure 2. Effect of in vitro pyrrolidinedithiocarbamate (PDTC) treatment on IL-8 and GM-CSF release. Concentrations of GM-CSF $(A)$ and IL-8 $(B)$ produced by $\mathrm{PBMC}$ isolated from children with moderate persistent asthma cultivated for 24 hours in the absence or presence of $500 \mathrm{mM}$ PDTC. Individual data are shown. Horizontal lines represent the medians. Closed triangles: low producers, children with moderate persistent asthma. Open triangles: high producers, children with moderate persistent asthma. Closed circles: children with noncompliant moderate persistent asthma. Statistical analysis and $p$ values were assessed without including the noncompliant subject. asthma and normal children (p65: $\mathrm{p}<0.001$; $\mathrm{p}-\mathrm{IkB} \alpha$ : $\mathrm{p}<0.003$ and $\mathrm{p}<0.002$ ), (Figures 4 and 5). A significant correlation was found between IL- 8 and GM-CSF levels released by PBMC or FE NO and the amount of $\mathrm{p}-\mathrm{IkB} \alpha(\mathrm{p}<0.006, \mathrm{p}<0.005$, and $\mathrm{p}<0.02$, respectively; Spearman rank test) or p65 ( $\mathrm{p}<0.05, \mathrm{p}<$ 0.007 , and $\mathrm{p}<0.05$, respectively; Spearman rank test).

\section{Correlation between Biomarkers and Asthma Exacerbations}

In patients with moderate asthma, there were 39 exacerbations (mean 2.2 exacerbations per patient), of which 31 were moderate and eight severe. Three out of 17 patients did not have any exacerbation. IL-8, GM-CSF, and FE NO levels were significantly correlated with the number of exacerbations $(\mathrm{p}<0.004$, $\mathrm{p}<0.004$, and $\mathrm{p}<0.002$ ) (Figure 6). In addition, high producers had a significantly higher number of exacerbations (3.2/patient/ year) than low producers $(1 /$ patient/year $)(p<0.002)$. Moreover, only high producers experienced severe exacerbations. Likewise, an increased number of exacerbations was observed in three children with intermittent asthma who showed increased production of IL-8 and GM-CSF by PBMC as well as enhanced FE NO levels. Finally, the levels of cortisol were similar in high and low producers and did not significantly correlate with the levels of the biomarkers studied.

\section{DISCUSSION}

This study shows that the levels of several biomarkers, such as IL-8 and GM-CSF released by PBMC as well as NF-кB, p-IkB $\alpha$

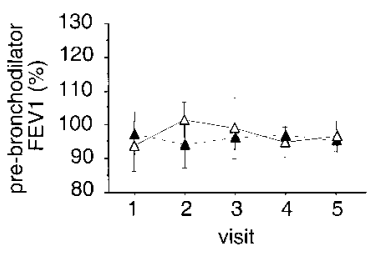

Figure 3. Mean (95\% confidence interval) $\mathrm{FEV}_{1}$ (\% of predicted) before and after bronchodilator in children with moderate asthma. $\mathrm{FEV}_{1}$ (\% of predicted) was measured at study entry (visit 1 ) and during the follow-up period at 3 (visit 2), 6 (visit 3), 12 (visit 4), and 18 (visit 5) months. Dotted lines and solid lines show the change of $\mathrm{FEV}_{1}$ in children with asthma, low and high producers, respectively. In high producer children with asthma, a statistical significant change was found comparing postbronchodilator $\mathrm{FEV}_{1}$ at visit 5 versus visits 2 and 3 (asterisk). ( $p<0.005$, by analysis of variance with Bonferroni's correction). The results are expressed as mean (95\% confidence interval) $\mathrm{FEV}_{1}$ before and after bronchodilator. 


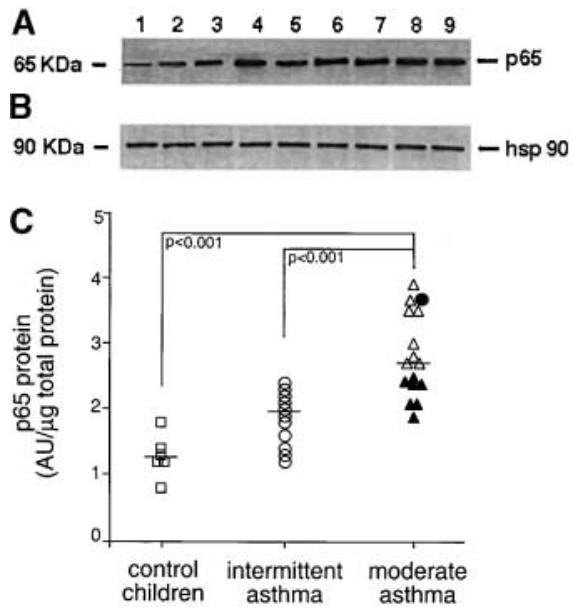

Figure 4. p65 protein expression in PBMC of normal children and children with intermittent and moderate asthma. $(A)$ Representative Western blot analysis of p65 in PBMC from two normal children (lanes 2 and 3), three children with intermittent asthma (lanes 4, 5, and 6), and three children with moderate asthma (lanes 7, 8, and 9). In lane 1, $5 \mathrm{mg}$ of total protein from A549 cells were loaded on the gel as reference for p65 expression. (B) The same blot was probed with a monoclonal antibody directed against Hsp90. (C) Signals corresponding to p65 on the various Western blots were semiquantified by densitometric scanning and normalized relatively to the amount of p65 in A549 cells. Horizontal lines represent the medians. Closed triangles: low producers, children with moderate persistent asthma. Open triangles: high producers, children with moderate persistent asthma. Closed circles: children with noncompliant moderate persistent asthma. Statistical analysis and $p$ values were assessed without including the noncompliant subject.

and FE NO, are significantly higher in children with intermittent and moderate persistent asthma than in healthy control children. In addition, this study suggests that two different subgroups of children with moderate asthma can be identified according to the levels of biomarkers measured. Although inhaled corticosteroids are highly effective in children with asthma, some patients are not fully controlled, probably because of an ongoing inflammation. We therefore designed this pilot study to assess longitudinally asthma control in children with moderate asthma and to investigate the predictive value of several inflammatory biomarkers measured at study entry. In addition, to avoid any bias due to lack of adherence to treatment, compliance was assessed by measuring the levels of cortisol $(5,7,24)$ in children with both intermittent and moderate persistent asthma. Severity was also checked according to Global Initiative for Asthma 1995 guidelines to avoid any influence of a misclassification on the parameters assessed in the study.

This study shows the presence of a persistent inflammation in children with moderate asthma despite a treatment with high doses of inhaled corticosteroids. It was possible to identify two distinct subgroups of patients with moderate asthma characterized by high or low levels of inflammatory biomarkers. Patients of the "high producer" subgroup experienced a greater number of exacerbations and a greater decline in postbronchodilator $\mathrm{FEV}_{1}$ at the end of the study.

It is likely that the clear differences in clinical and biological parameters between children with intermittent and persistent asthmat reflect the selection of the subjects from two extremes of the asthma spectrum. In fact, patients classified as moderate persistent using the Global Initiative for Asthma 1995 classification should be ascribed to "severe asthmatics" in the new 2002 update of the Global Initiative for Asthma classification. It is also
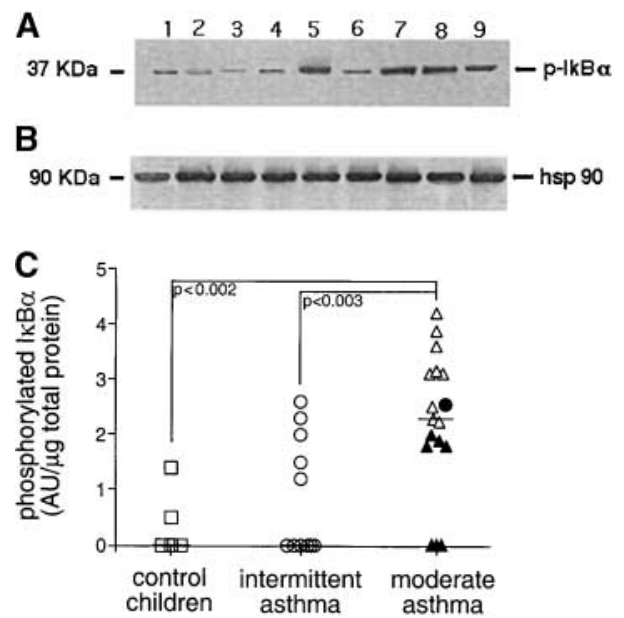

Figure 5. $\mathrm{p}-\mathrm{IkB} \alpha$ protein expression in PBMC of normal children, children with intermittent and moderate asthma. $(A)$ Representative Western blot analysis of $\mathrm{p}-\mathrm{IkB} \alpha$ in PBMC from two normal children (lanes 2 and 3 ), three children with intermittent asthma (lanes 4, 5, and 6), and three children with moderate asthma (lanes 7,8 , and 9). In lane $1,5 \mathrm{mg}$ of total protein from A549 cells were loaded on the gel as reference for $\mathrm{p}-\mathrm{lkB} \alpha$ expression. $(B)$ The same blot was probed with a monoclonal antibody directed against $\mathrm{Hsp} 90$. (C) Signals corresponding to $\mathrm{p}-\mathrm{lkB} \alpha$ on the various Western blots were semiquantified by densitometric scanning and normalized relatively to the amount of $p-I k B \alpha$ in A549 cells. Horizontal lines represent the medians. Closed triangles: low producers moderate persistent asthmatics. Open triangles: high producers moderate persistent asthmatics. Closed circles: children with noncompliant moderate persistent asthma. Statistical analysis and $p$ values were assessed without including the noncompliant subject.

likely that a number of these patients may fall into the category of "steroid insensitive" because despite the high dose of inhaled corticosteroid they are still having relapses and require courses of oral corticosteroid.

This study also shows that in some patients, at recommended doses, inhaled corticosteroids do not completely inhibit all inflammatory cellular and molecular mechanisms underlying airway inflammation. In some patients with moderate persistent

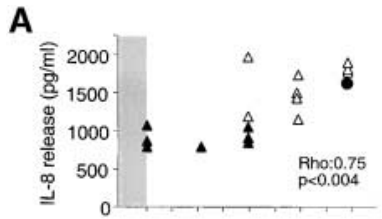

Figure 6. Correlations between number of exacerbations and levels of inflammatory mediators. Correlations between number of exacerbations and $(A)$ IL-8 release by PBMC isolated from
B

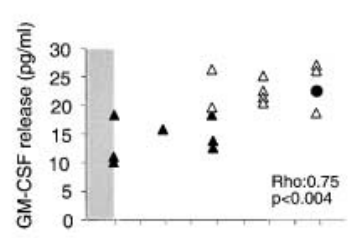

C

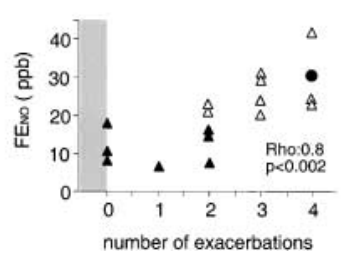
children with moderate asthma, $(B)$ GM-CSF release by PBMC isolated from children with moderate asthma, and (C) FE NO in children with moderate asthma. Closed triangles: low producers, children with moderate persistent asthma. Open triangles: high producers, children with moderate persistent asthma. Closed circles: children with noncompliant moderate persistent asthma. Statistical analysis and $p$ values were assessed without including the noncompliant subject. 
asthma, an increased activation of NF-кB was demonstrated by the overexpression of $\mathrm{p} 65$ subunit. On inflammatory activation, $\mathrm{IkB} \alpha$ is phosphorylated and proteolyzed, resulting in release of $\mathrm{NF}-\kappa \mathrm{B}$ dimers from the cytoplasmic NF- $\mathrm{B} / \mathrm{IkB}$ complex and translocation to the nucleus. The de novo synthesis of $\operatorname{IkB} \alpha$ after degradation inhibits NF-кB in the absence of a new signal (27). Enhanced $\mathrm{IkB} \alpha$ phosphorylation, observed in some children with asthma, suggests that resynthesized $\mathrm{IkB} \alpha$ is constantly phosphorylated by incoming inflammatory stimuli. The excess of active NF- $\mathrm{B}$ resulting from the high level of $\mathrm{p} 65$ and $\mathrm{p}-\mathrm{IkB} \alpha$ could induce an increased production of IL-8 and GM-CSF. In agreement with this hypothesis, we found that the increased release of IL-8 and GM-CSF by PBMC isolated from children with moderate asthma was significantly reduced after the in vitro treatment with the specific NF- $\mathrm{kB}$ inhibitor, pyrrolidinedithiocarbamate. In addition, the levels of $\mathrm{p}-\mathrm{IkB} \alpha$ protein were significantly correlated with those of p65 as well as with the amount of GM-CSF or IL-8 released by PBMC and FE NO. Furthermore, the persistent release of GM-CSF and IL- 8 may also indicate a greater propensity of the "high producers" to develop severe asthma $(13,28)$ and could contribute to neutrophilic inflammation, which is often associated with this asthma phenotype $(13,28)$. Interestingly, a similar pattern of activation of the $\mathrm{NF}-\kappa \mathrm{B} / \mathrm{IkB} \alpha$ system was found in a few children with intermittent asthma who not only showed a greater production of inflammatory biomarkers but also a higher number of asthma exacerbations during the 18 months of follow-up.

Finally, as far as cortisol is concerned, at 8:00 A.M., the normal levels of basal plasma cortisol concentrations range from 135-170 to $690-800 \mathrm{nM} / \mathrm{L}(29,30)$. Although all but three children with intermittent asthma had basal cortisol level above this normal range, children with intermittent asthma showed lower morning cortisol levels than did normal children. There are several possible explanations for this finding. The first is that low cortisol levels may reflect loss of asthma control (31). Interestingly, in the present study, the three subjects having lower basal cortisol levels were the same who showed an increase of inflammatory biomarkers as well as of number of exacerbations, suggesting that lower cortisol levels in asthmatic children influence asthma control, possibly due to a lack of suppression of airway inflammation (31). We found that there is a trend toward a correlation between cortisol levels and GM-CSF, but it did not reach a statistical significance $(\mathrm{p}=0.078)$. However, this finding points out the potential implication of cortisol in the regulation of inflammation in intermittent asthma and the need to better explore this issue in a larger cohort of intermittent asthmatics. Another possible explanation is that some of these subjects received inhaled corticosteroids either before or during the study without informing the clinical investigator. We believe, however, that if this occurred, inhaled steroids were possibly received on a very irregular basis because all the subjects attended our outpatient clinic regularly. In addition, whether or not this may have caused a reduction of cortisol levels is not clear.

We also acknowledge that there is a high decrease of cortisol levels in children with persistent asthma treated with $500 \mu \mathrm{g}$ fluticasone propionate. This finding may be due to (1) the enhanced absorption of the drug via the respiratory tract as well as by the enhanced fluticasone propionate binding to the glucocorticoid receptor (32); (2) the long-term treatment with high doses (>400 $\mu \mathrm{g})$ of fluticasone propionate, as already reported in a previous study (22); (3) the effects of a short course of oral corticosteroids ( $1 \mathrm{mg} / \mathrm{kg}$ of prednisolone for 5 days), which were administered during severe exacerbations (1). In conclusion, this study shows that children with moderate (or severe) asthma can be differentiated into subgroups according to biological and clinical parameters and suggests that the amount of IL- 8 and GM-CSF released by PBMC as well as the levels of NF-кB, p-IkB $\alpha$, and FE NO may be useful to assess clinical heterogeneity in children with moderate asthma. This study also proposes the need to perform large prospective studies to confirm the importance of measuring peripheral blood markers to assess airway inflammation and asthma control in children with asthma.

\section{References}

1. Barbato A, Panizzolo C, Gheno M, Sainati L, Favero E, Faggian D, Giusti F, Pesscolderungg L, La Rosa M. Bronchoalveolar lavage in asthmatic children: evidence of neutrophil activation in mild-to-moderate persistent asthma. Pediatr Allergy Immunol 2001;12:73-77.

2. Marguet C, Jouen-Boedes F, Dean TP, Warner JO. Bronchoalveolar cell profiles in children with asthma, infantile wheeze, chronic cough, or cystic fibrosis. Am J Respir Crit Care Med 1999;159:1533-1540.

3. Marguet C, Dean TP, Basuyau JP, Warner JO. Eosinophil cationic protein and interleukin-8 levels in bronchial lavage fluid from children with asthma and infantile wheeze. Pediatr Allergy Immunol 2001; 12:27-33.

4. Szefler SJ, Martin RJ, King TS, Boushey HA, Cherniack RM, Chinchilli VM, Craig TJ, Dolovich M, Drazen JM, Fagan JK, et al. Significant variability in response to inhaled corticosteroids for persistent asthma. J Allergy Clin Immunol 2002;109:410-418.

5. Payne DN, Balfour-Lynn IM. Children with difficult asthma: a practical approach. J Asthma 2001;38:189-203.

6. Chan MT, Leung DY, Szefler SJ, Spahn JD. Difficult-to-control asthma: clinical characteristics of steroid-insensitive asthma. J Allergy Clin Immunol 1998;101:594-601.

7. Payne DN, Wilson NM, James A, Hablas H, Agrafioti C, Bush A. Evidence for different subgroups of difficult asthma in children. Thorax 2001;56:345-350.

8. Barnes PJ, Karin M. Nuclear factor-kB: a pivotal transcription factor in chronic inflammatory diseases. N Engl J Med 1997;336:1066-1071.

9. Vignola AM, Chiappara G, Siena L, Bruno A, Gagliardo R, Merendino AM, Polla BS, Arrigo AP, Bonsignore G, Bousquet J, et al. Proliferation and activation of bronchial epithelial cells in corticosteroid-dependent asthma. J Allergy Clin Immunol 2001;108:738-746.

10. Hart LA, Krishnan VL, Adcock IM, Barnes PJ, Chung KF. Activation and localization of transcription factor, nuclear factor- kappaB, in asthma. Am J Respir Crit Care Med 1998;158:1585-1592.

11. Rothwarf DM, Karin M. The NF-kappa B activation pathway: a paradigm in information transfer from membrane to nucleus. Sci STKE 1999; 1999:RE1.

12. Vachier I, Chiappara G, Vignola AM, Gagliardo R, Altieri E, Terouanne B, Vic P, Bousquet J, Godard P, Chanez P. Glucocorticoid receptors in bronchial epithelial cells in asthma. Am J Respir Crit Care Med 1998; 158:963-970.

13. Gagliardo R, Chanez P, Vignola AM, Bousquet J, Vachier I, Godard P, Bonsignore G, Demoly P, Mathieu M. Glucocorticoid receptor alpha and beta in glucocorticoid dependent asthma. Am J Respir Crit Care Med 2000;162:7-13.

14. Massaro AF, Gaston B, Kita D, Fanta C, Stamler JS, Drazen JM. Expired nitric oxide levels during treatment of acute asthma. Am J Respir Crit Care Med 1995;152:800-803.

15. Barnes PJ. Inhaled glucocorticoids for asthma. N Engl J Med 1995;332: 868-875.

16. Sont JK, Willems LN, Bel EH, van Krieken JH, Vandenbroucke JP, Sterk PJ. Clinical control and histopathologic outcome of asthma when using airway hyperresponsiveness as an additional guide to long-term treatment: the AMPUL Study Group. Am J Respir Crit Care Med 1999; 159:1043-1051.

17. Schreck R, Meier B, Mannel DN, Droge W, Baeuerle PA. Dithiocarbamates as potent inhibitors of nuclear factor kappa B activation in intact cells. $J$ Exp Med 1992;175:1181-1194.

18. Global strategy for asthma management and prevention. WHO/NHLBI workshop report. National Institutes of Health, National Heart, Lung, and Blood Institute, Publication Number 95-3659 1995.

19. Standards for the diagnosis and care of patients with chronic obstructive pulmonary disease (COPD) and asthma. This official statement of the American Thoracic Society was adopted by the ATS Board of Directors, November 1986. Am Rev Respir Dis 1987;136:225-244.

20. Polgar G. Pulmonary function tests in children. J Pediatr 1979;95:168-170.

21. Dreborg S. Skin testing: the safety of skin tests and the information obtained from using different methods and concentrations of allergen. Allergy 1993;48:473-475. 
22. Eid N, Morton R, Olds B, Clark P, Sheikh S, Looney S. Decreased morning serum cortisol levels in children with asthma treated with inhaled fluticasone propionate. Pediatrics 2002;109:217-221.

23. Lipworth BJ, Jackson CM. Safety of inhaled and intranasal corticosteroids: lessons for the new millennium. Drug Saf 2000;23:11-33.

24. Hagg E, Asplund K, Lithner F. Value of basal plasma cortisol assays in the assessment of pituitary-adrenal insufficiency. Clin Endocrinol (Oxf) 1987;26:221-226.

25. Recommendations for standardized procedures for the on-line and offline measurement of exhaled lower respiratory nitric oxide and nasal nitric oxide in adults and children-1999: this official statement of the American Thoracic Society was adopted by the ATS Board of Directors, July 1999. Am J Respir Crit Care Med 1999;160:2104-2117.

26. Pauwels RA, Lofdahl CG, Postma DS, Tattersfield AE, O'Byrne P, Barnes PJ, Ullman A. Effect of inhaled formoterol and budesonide on exacerbations of asthma. Formoterol and Corticosteroids Establishing Therapy (FACET) International Study Group. N Engl J Med 1997;337: 1405-1411.
27. Brown K, Park S, Kanno T, Franzoso G, Siebenlist U. Mutual regulation of the transcriptional activator NF-kappa B and its inhibitor, I kappa B-alpha. Proc Natl Acad Sci USA 1993;90:2532-2536.

28. Wenzel SE, Szefler SJ, Leung DY, Sloan SI, Rex MD, Martin RJ. Bronchoscopic evaluation of severe asthma: persistent inflammation associated with high dose glucocorticoids. Am J Respir Crit Care Med 1997; 156:737-743.

29. Lacroix A, Clavier A. The adrenal cortex: basic concepts and diagnostic procedures. In: Pinchera A, editor. Endocrinology and metabolism. Milan: McGraw-Hill; 2001. p. 290-296.

30. Sizonenko PC. Effects of inhaled or nasal glucocorticosteroids on adrenal function and growth. J Pediatr Endocrinol Metab 2002;15:5-26.

31. Landstra AM, Postma DS, Boezen HM, van Aalderen WM. Role of serum cortisol levels in children with asthma. Am J Respir Crit Care Med 2002;165:708-712.

32. Todd G, Dunlop K, McNaboe J, Ryan MF, Carson D, Shields MD. Growth and adrenal suppression in asthmatic children treated with highdose fluticasone propionate. Lancet 1996;348:27-29. 